\title{
Correction to: Diosmetin induces apoptosis in ovarian cancer cells by activating reactive oxygen species and inhibiting the Nrf2 pathway
}

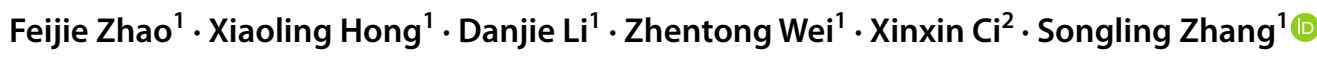

Published online: 4 June 2021

○) Springer Science+Business Media, LLC, part of Springer Nature 2021

Correction to: Medical Oncology (2021) 38:54

https://doi.org/10.1007/s12032-021-01501-1

The original version of this article unfortunately contained a mistakes in Fig. 2B and Fig. 4A. The correct figures are given below.

The original article can be found online at https://doi.org/10.1007/ s12032-021-01501-1.

Xinxin $\mathrm{Ci}$

cixinxin@jlu.edu.cn

$\triangle$ Songling Zhang

slzhang@jlu.edu.cn

1 Department of Obstetrics and Gynecology, The First

Hospital of Jilin University, Xinmin Road 519, Changchun, Jilin 130001, China

2 Institute of Translational Medicine, The First Hospital of Jilin University, Dongminzhu Road 71, Changchun, Jilin 130001, China 
Fig. 1 Diosmetin (Dio) inhibits the migration and invasion of ovarian cancer cells. b The effect of Dio on cell migration was assessed via the woundhealing assay. The cells were treated with various concentrations of Dio for $24 \mathrm{~h}$. Images were taken under a microscope $(10 \times 10)$. Scale bar $=100 \mu \mathrm{m}$
A

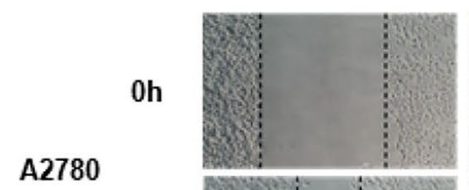

$24 h$

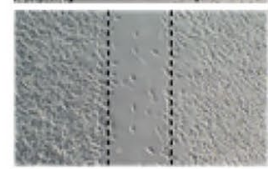

C

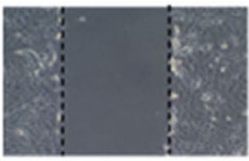

10

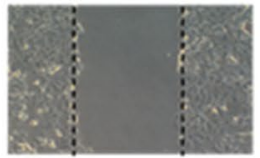

$24 h$
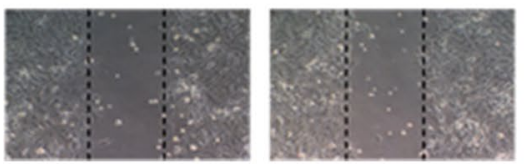

20
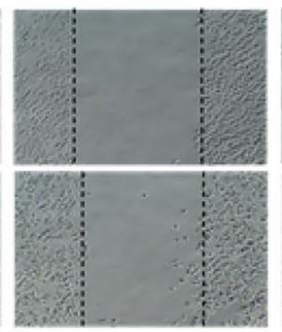

20
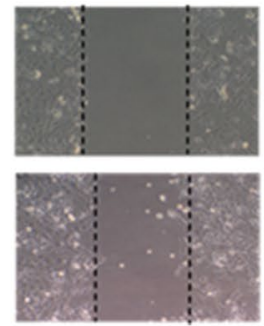

$40(\mu \mathrm{M})$

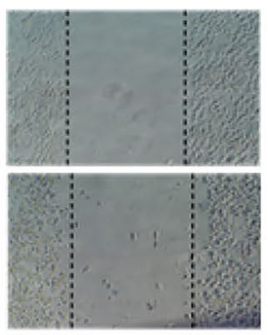

$40(\mu \mathrm{M})$
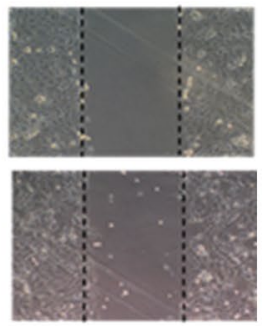

C

C

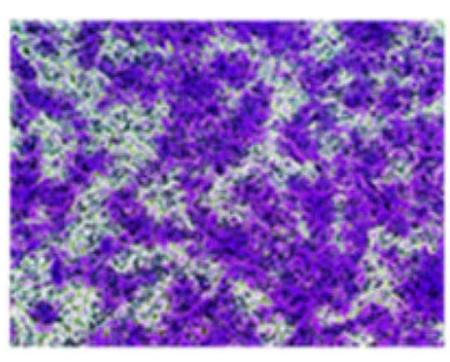

A2780

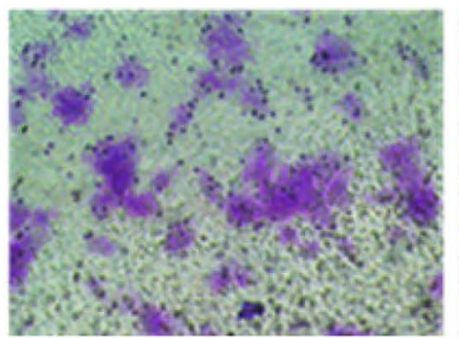

Dio
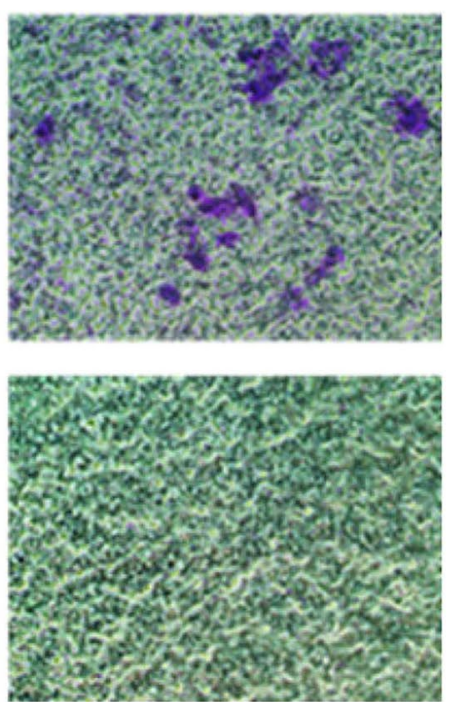
A
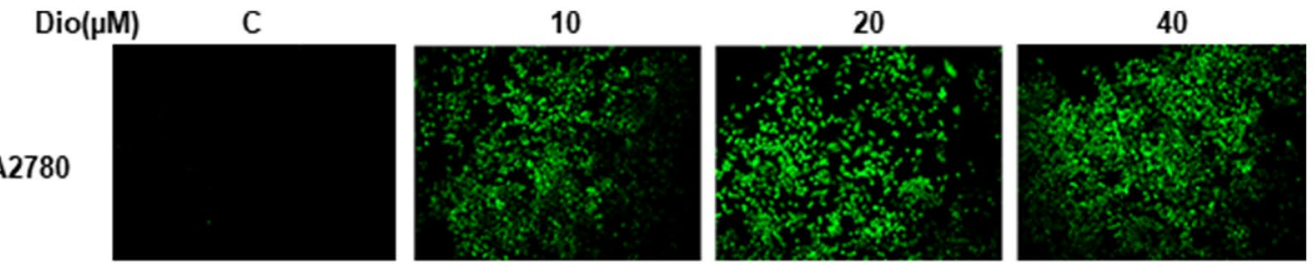

SKOV3
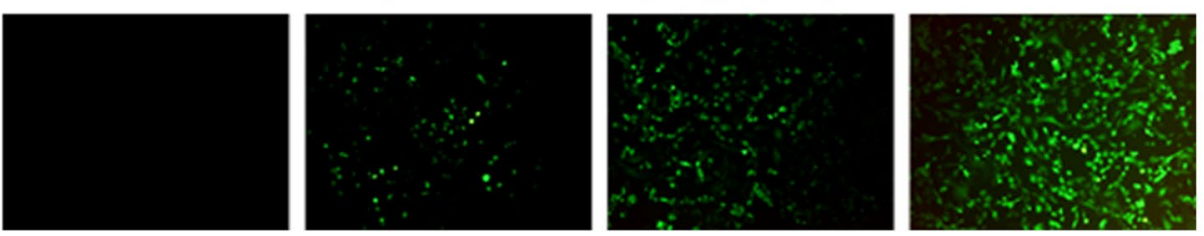

B

C
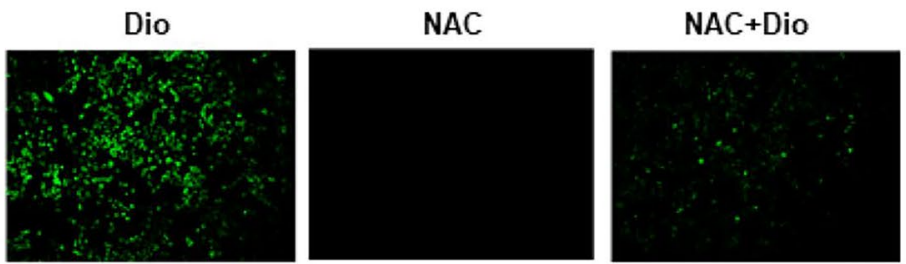

SKOV3
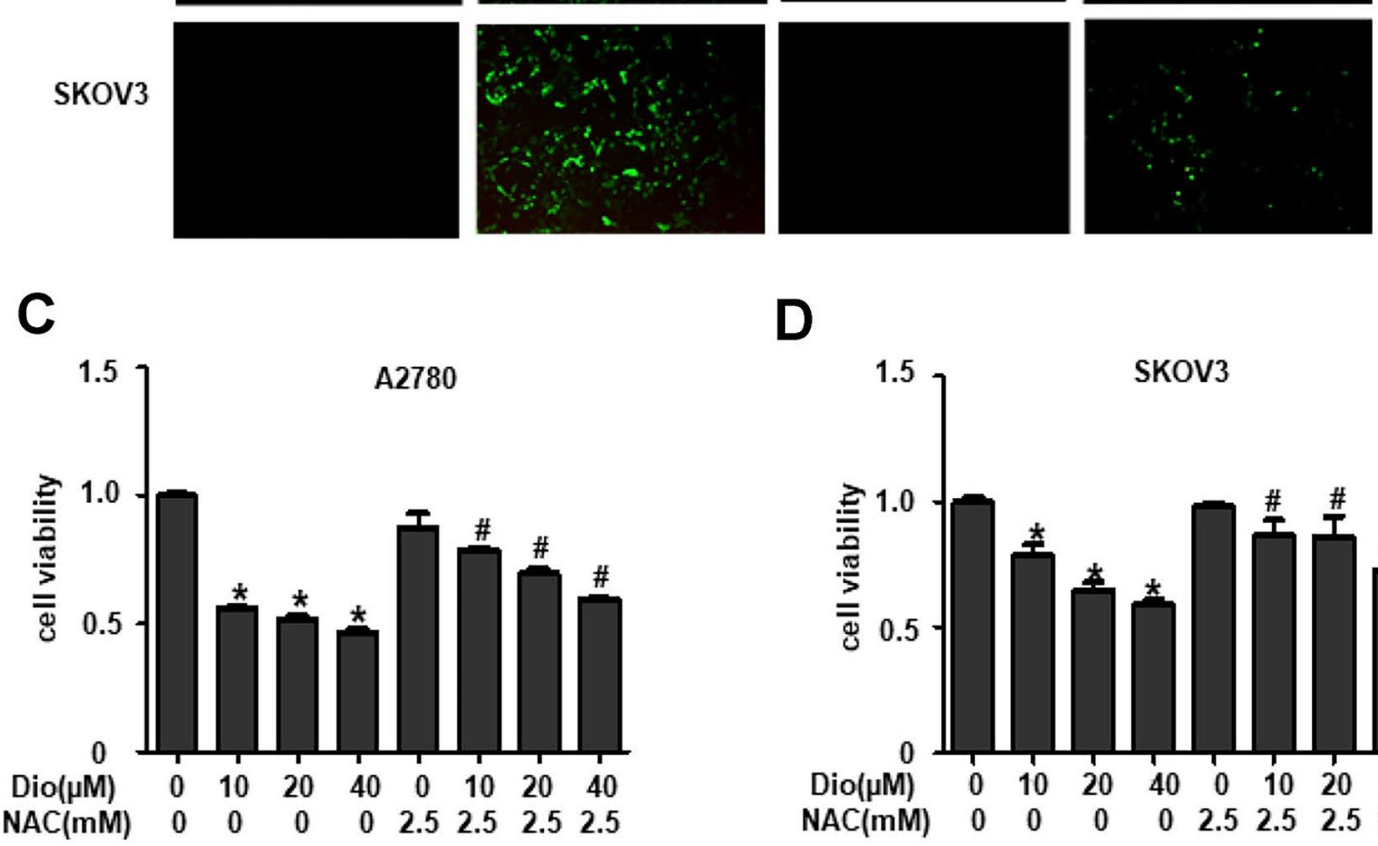

D

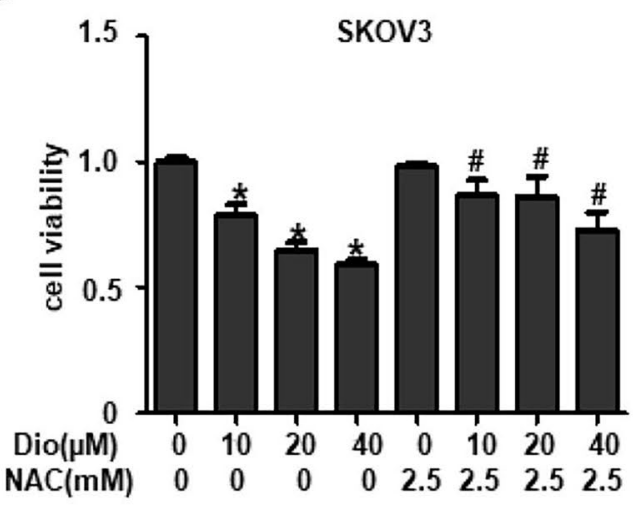

$\mathbf{E}$
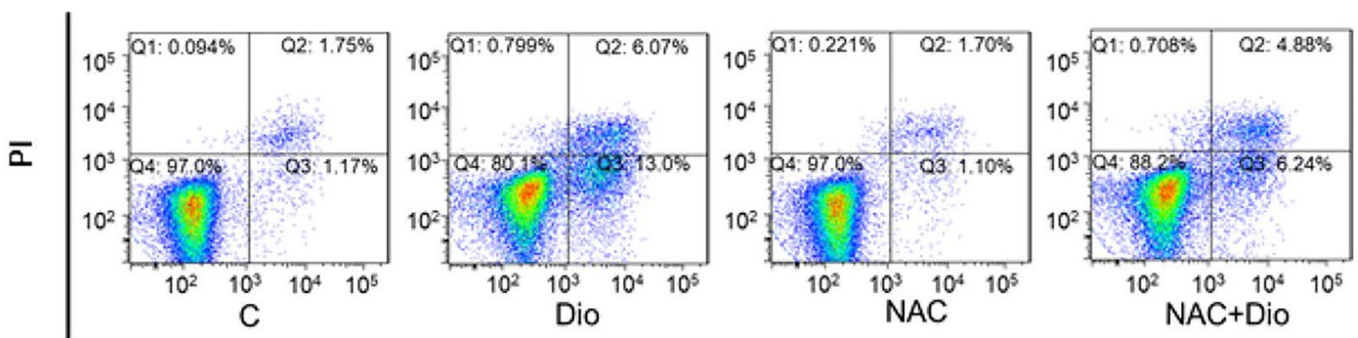

\section{Annexin V-FITC}

Fig. 2 Diosmetin (Dio) reduces the viability and induces the apoptosis of ovarian cancer cells by upregulating reactive oxygen species (ROS) levels. a and b A2780 and SKOV3 cells were pre-treated with or without N-acetyl-L-cysteine (NAC) and then treated with Dio. Afterward, the cells were stained with DCFH-DA. The images were collected under a fluorescence microscope $(10 \times 10)$. Scale bar $=100 \mu \mathrm{m}$ 
Publisher's Note Springer Nature remains neutral with regard to jurisdictional claims in published maps and institutional affiliations. 